\title{
Editorial: CephsInAction: Towards Future Challenges for Cephalopod Science
}

\author{
Lindy Holden-Dye ${ }^{1}$, Giovanna Ponte ${ }^{2,3}$, A. Louise Allcock ${ }^{4}$, Erica A. G. Vidal ${ }^{5}$, \\ Ryuta Nakajima ${ }^{6}$, Tarla Rai Peterson ${ }^{7}$ and Graziano Fiorito ${ }^{3 *}$ \\ ${ }^{1}$ School of Biological Sciences, University of Southampton, Southampton, United Kingdom, ${ }^{2}$ Association for Cephalopod \\ Research 'CephRes', Naples, Italy, ${ }^{3}$ Department of Biology and Evolution of Marine Organisms, Stazione Zoologica Anton \\ Dohrn, Naples, Italy, ${ }^{4}$ Ryan Institute, National University of Ireland Galway, Galway, Ireland, ${ }^{5}$ Centro de Estudos do Mar, \\ Universidade Federal do Paraná (UFPR), Pontal do Paraná, Brazil, ${ }^{6}$ University of Minnesota Duluth, Duluth, MN, \\ United States, ${ }^{7}$ The University of Texas at El Paso, El Paso, TX, United States
}

Keywords: cephalopods, invertebrates, welfare, outreach, communication, neuroscience, physiology

\section{Editorial on the Research Topic}

\section{CephsInAction: Towards Future Challenges for Cephalopod Science}

\section{OPEN ACCESS}

Edited and reviewed by: Sylvia Anton, Institut National de la Recherche Agronomique (INRA), France

*Correspondence: Graziano Fiorito graziano.fiorito@szn.it

Specialty section:

This article was submitted to Invertebrate Physiology, a section of the journal Frontiers in Physiology

Received: 16 June 2019 Accepted: 11 July 2019 Published: 25 July 2019

Citation: Holden-Dye L, Ponte G, Allcock AL, Vidal EAG, Nakajima $R$, Peterson TR and Fiorito $G$ (2019) Editorial:

CephsInAction: Towards Future Challenges for Cephalopod Science.

Front. Physiol. 10:980.

doi: 10.3389/fphys.2019.00980
The collection of papers included in this Research Topic represents the outcome of one of the activities of the COST Action FA1301-“A network for improvement of cephalopod welfare and husbandry in research, aquaculture, and fisheries" (CephsInAction) - that operated for 4 years from 2013 to 2017. The idea of a "CephsInAction" Research Topic entitled "Towards Future Challenges for Cephalopod Science" emerged at one of the last meetings of the COST Action FA1301: CephsInAction and CIAC Meeting "Cephalopod Science from Biology to Welfare" (Hellenic Centre for Marine Research, Heraklion, Crete, Greece, 28-31 March 2017), and from some editorial initiatives discussed at that time. This Research Topic (RT) is just one example of several RTs, and indeed other separate papers, dedicated to cephalopod molluscs (Hanke and Osorio, 2018; Ponte et al., 2018) ${ }^{2}$ that have been hosted by Frontiers over the last few years.

This highlighting of cephalopod science is important as it has much to offer not only the life sciences community, but also more broadly the public perception of science and its understanding and relationship with scientific endeavor. To make this contribution, there are logistical challenges facing the cephalopod research community that need to be overcome. Importantly, given that cephalopod science is a relatively small, globally distributed research community, there is a need for rapid and effective mechanisms for exchange of knowledge and resources, encompassing everything from the sharing of laboratory protocols, videos, tissues and samples, and data-sets to innovation in public engagement. This also presents strategic challenges in convincing globally distributed policy makers and funders of the relevance of cephalopods in scientific advances. There are regulatory aspects too, as cephalopods are the only invertebrates whose use is regulated in Europe in a research context (e.g., Fiorito et al., 2014, 2015; Di Cristina et al., 2015), which increases the need for an integrated oversight and direction in terms of ethics and animal welfare (Ponte et al., 2019). This links to the important recognition that cephalopods are not "simple" laboratory

\footnotetext{
${ }^{1}$ http://www.cephsinaction.org/activities/meetings/year2016/cephsinactioncretaquarium/

${ }^{2}$ see also: https://www.frontiersin.org/research-topics/10233/vision-in-cephalopods-part-ii; https://www.frontiersin.org/ research-topics/9997/cephalopod-research-across-scales---molecules- to-ecosystems
} 
animals and that we need to understand their physiology and behavior by intersecting studies in their natural environment with those in standardized settings such as the lab-bench. Only by a better understanding of the normal range of behaviors of distinct species of cephalopods can their welfare be improved. There is the need for better phylogenetic resolution and for more accurate field data to facilitate this.

This Research Topic also aligns with the interests of the cephalopod community in stimulating public interest in cephalopods and their artistic interpretation. This extends to a broader audience that could include chefs and gourmets ${ }^{3}$, fishers and scientists aiming to develop sustainable food resources. School children's natural fascination with cephalopods (e.g., Sperduti et al., 2012) can excite their interest in scientific discovery and encourage them to engage in conversations about the scientific process and what it means. The importance of such conversations cannot be underestimated in a world in which the public needs to be scientifically literate, as they must be equipped to make important socio-economical and political decisions facing the current condition of the world, whilst being confronted with 'fake news', 'alternative truths', and when expert opinion is often derided. There is great potential for innovative schemes for public engagement that springs from the natural wonderment the cephalopods incite.

The last five years have been extremely challenging, but also very innovative for cephalopod science and have continued the outstanding tradition of biological contribution with cephalopod molluscs as key players (e.g., Keynes, 1989; De Sio, 2011; Albertin et al., 2012; Garrett and Rosenthal, 2012; Huffard, 2013; Liscovitch-Brauer et al., 2017; Marini et al., 2017; Sanchez et al., 2018).

This Research Topic includes 13 papers from about 40 authors representing ten different countries, thus overlapping with the original parties that contributed to the COST FA1301. Three papers present original data and 10 others are reviews and perspective articles on various topics, as examples of the interest that humans have for these fascinating marine molluscs. This Research Topic offers a journey that spans cephalopod gastronomy (Mouritsen and Styrbæk) offering a glance at the interest among chefs and gastroscientists to explore these organisms as a counterpoint to other seafood, a look at new protein sources to replace meat from landanimal production, and a test of texture and flavor properties of cuttlefish, squid and octopus and how these provide the ground for a variety of culinary transformations. "CephsInAction: Towards Future Challenges for Cephalopod Science" also offers an "OctopusEye,": a "refracted spectatorship" perspective and conceptual analysis of the film "The Love Life of the

\footnotetext{
${ }^{3}$ See for example the Atlantic Area Interreg Project "Cephs and Chefs" https:// www.cephsandchefs.com/
}

\section{REFERENCES}

Albertin, C. B., Bonnaud, L., Brown, C. T., Crookes-Goodson, W. J., da Fonseca, R. R., Di Cristo, C., et al. (2012). Cephalopod genomics: a plan of strategies and organization. Stand. Genomic Sci. 7, 175-188. doi: 10.4056/sigs.3136559
Octopus (Les Amours de la pieuvre) (1965)" (Hayward). But cephalopods are also at the boundaries between "science, art and engineering" (Nakajima et al.). They are among the most enthusiastically visited animals in public aquaria, providing a way of communicating science and conservation (Marchio), and offer various "Critical Challenges Ahead" (O'Brien et al.) as envisioned by three junior "researchers who have recently embarked on careers in cephalopod biology" and that provide their suggestions on a variety of topics spanning from genetics, to welfare, behavior, cognition, and neurobiology.

This volume includes studies on the effects of maternal and embryonic stress on the behavior of offspring (Sepia officinalis, O'Brien et al.), presenting evidence for age-related differences in defensive behaviors in the sepiolid Euprymna (Seehafer et al.), or the development of swimming abilities of paralarvae of Doryteuthis opalescens (Vidal et al.). A preliminary analysis of the expression of protocadherins in Octopus vulgaris is also included providing the ground for future analysis of the way these genes may drive neural wiring during development and in the cases of biological and neural plasticity in the adult (Styfhals et al.).

Finally, several reviews are included in this Research Topic, (i) examining parasites that cephalopod host, (ii) raising the possibility of the existence of stem cells in cephalopod brains, (iii) considering possible cases of functional and convergent evolution of neural-systems, when compared with vertebrates, and (iv) overviewing the extraordinary and historically well-studied biological cases of tissue and neural regeneration (Deryckere and Seuntjens; Imperadore and Fiorito; Roumbedakis et al.; Shigeno et al.).

In sum, all contributions reflect a broad, interdisciplinary active and vital scientific community.

\section{AUTHOR CONTRIBUTIONS}

All authors listed have made a substantial, direct and intellectual contribution to the work, and approved it for publication.

\section{ACKNOWLEDGMENTS}

This editorial and the e-book are based upon collaboration under the COST Action FA1301 CephsInAction that also supported the meeting and partially funded the open access costs of the papers included in this RT. The Association for Cephalopod Research CephRes supported this work. We are deeply thankful to the CretAquarium (Heraklion) for help for the organization of the meeting, and in particular to Dr. Panagiotis Grigoriou and Dr. Aspasia Sterioti. We are also grateful to Dr. C. Balestrieri (CephRes) for her scientific and managerial assistance. The studies included herein are considered a contribution to the COST (European COoperation on Science and Technology) Action FA1301.

De Sio, F. (2011). Leviathan and the soft animal: Medical humanism and the invertebrate models for higher nervous functions, 1950s-90s. Med. Hist. 55, 369-374. doi: 10.1017/S0025727300005421

Di Cristina, G., Andrews, P., Ponte, G., Galligioni, V., and Fiorito, G. (2015). The impact of Directive 2010/63/EU on cephalopod 
research. Invert. Neurosci. 15, 8. doi: 10.1007/s10158-0150183-y

Fiorito, G., Affuso, A., Anderson, D. B., Basil, J., Bonnaud, L., Botta, G., et al. (2014). Cephalopods in neuroscience: regulations, Research and the 3Rs. Invert. Neurosci. 14, 13-36. doi: 10.1007/s10158-013-0165-x

Fiorito, G., Affuso, A., Basil, J., Cole, A., de Girolamo, P., D’Angelo, L., et al. (2015). Guidelines for the care and welfare of cephalopods in research - A consensus based on an initiative by CephRes, FELASA and the Boyd Group. Lab. Anim. 49, 1-90. doi: 10.1177/0023677215580006

Garrett, S., and Rosenthal, J. J. C. (2012). RNA editing underlies temperature adaptation in $\mathrm{K}^{+}$channels from polar octopuses. Science 335, 848. doi: $10.1126 /$ science. 1212795

Hanke, F. D., and Osorio, D. C. (2018). Editorial: Vision in Cephalopods. Front. Physiol. 9:18. doi: 10.3389/fphys.2018.00018

Huffard, C. L. (2013). Cephalopod neurobiology: an introduction for biologists working in other model systems. Invert. Neurosci. 13, 11-18. doi: 10.1007/s10158-013-0147-z

Keynes, R. D. (1989). The role of giant axons in studies of the nerve impulse. Bioessays 10, 90-93.

Liscovitch-Brauer, N., Alon, S., Porath, H. T., Elstein, B., Unger, R., Ziv, T., et al. (2017). Trade-off between transcriptome plasticity and genome evolution in cephalopods. Cell 169, 191-202.e111. doi: 10.1016/j.cell.2017.03.025.

Marini, G., De Sio, F., Ponte, G., and Fiorito, G. (2017). "Behavioral analysis of learning and memory in cephalopods," in Learning and Memory: A Comprehensive Reference, 2nd Edn, ed J. H. Byrne (Amsterdam: Academic Press; Elsevier), 441-462.
Ponte, G., Almansa, E., and Andrews, P. L. R. (2018). Editorial: the digestive tract of cephalopods: at the interface between physiology and ecology. Front. Physiol. 9:1409. doi: 10.3389/fphys.2018.01409

Ponte, G., Andrews, P., Galligioni, V., Pereira, J., and Fiorito, G. (2019). "Cephalopod welfare, biological and regulatory aspects: an EU experience," in The Welfare of Invertebrate Animals, eds C. Carere and J. A. Mather (Basel: Springer Nature Switzerland AG), 209-228.

Sanchez, G., Setiamarga, D. H. E., Tuanapaya, S., Tongtherm, K., Winkelmann, I. E., Schmidbaur, H., et al. (2018). Genus-level phylogeny of cephalopods using molecular markers: current status and problematic areas. PeerJ 6:e4331. doi: $10.7717 /$ peerj.4331

Sperduti, A., Crivellaro, F., Rossi, P. F., and Bondioli, L. (2012). "Do octopuses have a brain?" Knowledge, perceptions and attitudes towards neuroscience at school. PLOS ONE 7:e47943. doi: 10.1371/journal.pone.0047943

Conflict of Interest Statement: The authors declare that the research was conducted in the absence of any commercial or financial relationships that could be construed as a potential conflict of interest.

Copyright (c) 2019 Holden-Dye, Ponte, Allcock, Vidal, Nakajima, Peterson and Fiorito. This is an open-access article distributed under the terms of the Creative Commons Attribution License (CC BY). The use, distribution or reproduction in other forums is permitted, provided the original author(s) and the copyright owner(s) are credited and that the original publication in this journal is cited, in accordance with accepted academic practice. No use, distribution or reproduction is permitted which does not comply with these terms. 